\title{
Nipple Areola Kompleks Yerleșimli Meme Kanseri Cerrahi Tedavisinde Batwing Mastopeksi Tekniği
}

\author{
Batwing Mastopexy Technique in the Surgical Treatment of Nipple Areola Complex Breast Cancer
}

\section{Sami AÇAR ${ }^{1}$}

\author{
1. Zeynep Kamil Kadın ve Çocuk Hastalıkları Eüitim ve Araştırma Hastanesi, İstanbul, Türkiye
}

\section{$\ddot{O Z Z T}$}

Onkoplastik meme cerrahisinin amacl, meme kanseri dokusunu memenin seklini bozmadan negatif cerrahi sinırlarla çıkarmaktır. Onkolojik prensiplerden taviz vermeden, yeniden sekillendirme tekniklerini en iyi sekilde uygulamay gerektirir. Memenin yeniden şekillendirilmesi ise hasta için ayrıca ikincil kazançtır.

Giriş: Nipple areola kompleksini içeren meme kanserinin cerrahi tedavisinde Batwing Mastopeksi tekniği (Yarasa kanad tekniği) başart ile uygulanabilmektedir. Doğru endikasyonlarda bașarll kozmetik sonuçlar elde edilebilmektedir. Kaybedilen nipple areola kompleksinin yeniden oluşturulmast, genellikle onkolojik tedavi sonrasina birakılır. Radyoterapi ve kemoterapinin cilt üzerinde oluşturacağı hasarın boyutunu anlamak için bu daha akılcr olabilir.

Olgu: Premenapozal dönemde, ailesinde meme kanseri bulunmayan 48 yassında bayan hastada nipple komșuluğunda, areola tutulumu gösteren invaziv karsinom saptandı. Tümör meme hacmi oranının \%20'den fazla olması, santral yerleşimli tümör bulunmasi nedeniyle Batwing mastopeksi ile cerrahi tedavi yapıldl. Ameliyat sonrası dönemde yaklaşık üç hafta kadar memeyi destekleyecek, kendi beden numarasindan bir boy küçük sütyen giydirildi ve aynı dönemde günde iki defa oral deksketoprofen tablet verildi. Yara iyilesme sorunu yașanmadı ve onkolojik tedavi ameliyat sonrası dördüncü haftada başlandl.

Sonuç: Meme kanseri tanısı konan ve yapılacak tedavilerden haberdar edilen hastalar belirgin seviyede moral bozukluğuna uğramaktadır. Bir de memenin kaybedilmesi korkusu ayrı bir sikıntı yaşatmaktadır. Yapılan birçok çalışmada, meme kanseri cerrahi tedavisinin bașarll onkoplastik tekniklerle yapılmas sayesinde hasta memnuniyetinin belirgin düzeyde arttırıldiğ gösterilmistir. Hastalığın, memenin korunarak, uygun yeniden şekillendirme teknikleriyle tedavi edilmesi her cerrah için birincil amaç olmalıdır.

Anahtar Kelimeler: meme kanseri, meme koruyucu cerrahi, mamaplasti

\section{ABSTRACT}

The purpose of oncoplastic breast surgery is to remove breast cancer tissue with negative surgical margins without distorting the shape of the breast. It requires the best application of remodelling techniques without compromising the oncological principles. Remodelling of the breast is also a secondary benefit for the patient.

\section{İletişim}

Sorumlu Yazar: Sami AÇAR, Asst. Prof. Dr.

Adres: Zeynep Kamil Kadın ve Çocuk Hastalıkları Eğt. ve Arş. Hastanesi, Dr. B. Üstünel Sok, No:10, 34668 Üsküdar, İstanbul, Türkiye

Tel: +90 (532) 6306315

E-Posta: acarrsami@yahoo.com

Makale Geliş: 07.11.2020

Makale Kabul: 19.11.2020

DOI: http://dx.doi.org/ 10.16948/zktipb.822857
Introduction: Batwing mastopexy technique can be successfully performed in the surgical treatment of breast cancer involving the nipple areola complex. Successful results can be obtained in the right indications. Reconstitution of the lost nipple areola complex is usually performed after the oncological treatment. This approach might be more rational to understand the extent of the damage that radiotherapy and chemotherapy would cause on the skin.

Case: An invasive carcinoma with areola involvement was seen by the side of the nipple in a 48-year-old, premenauposal, female patient who had no family history of breast cancer. Surgical treatment was performed with the Batwing mastopexy technique due to the tumor breast volume ratio being more than $20 \%$ and the presence of centrally located tumor. In the postoperative period, a bra one size smaller than her own size was worn for three weeks. During the same period, dexketoprofen tablets were administered twice a day. There was no wound problem. Oncological treatment was begun in the fourth postoperative week.

Conclusion: Patients diagnosed with breast cancer and informed about the treatment modalities were significantly demoralized. The fear of losing the breast is an another reason for sadness. In many studies, it has been shown that patient satisfaction was significantly increased with successful oncoplastic techniques in breast cancer surgical treatment. Treatment of the disease with appropriate remodelling techniques and protecting the breast should be the primary goal for every surgeon.

Keywords: breast cancer, breast conserving surgery, mammoplasty

\section{GíRiș}

Meme koruyucu cerrahi, meme kanseri hastalarının \%60-80’ine uygulanabilmektedir [1]. Günümüzde bile azımsanmayacak oranda kadına tek ya da iki taraflı mastektomi yapılmaktadır. Ayrıca doğru açıklama yapılmaması sonucunda, hastalardan bir bölümü bunu talep etmektedir. Mastektomi sonrasında kozmetik görünüm, meme koruyucu cerrahi kadar önemlidir. Çünkü hastalar genel olarak tedavi sonrası uzun süre yaşamaktadır. Bu süreçte yaşam kalitesinin arttırılması, sağ kalım dışında memnuniyet sağlamaktadır.

Onkoplastik meme cerrahisi beceri seviyesine göre beș kategoriye ayrılmaktadır [2-5]. Çoğu tekniği meme cerrahisi uzmanı uygulayabilirken, karmaşık ve zor olgularda plastik cerrahın da bulunduğu ekip çalışması yapılması gerekmektedir. Planlama aşamasında elbette iyi radyolojik görüntüler elde edilmekte ve radyoloji uzmanının fikri alınmaktadır.

\section{OLGU}

48 yaşında bayan hasta, sağ meme başında yapılan tedavilerden fayda görmediği yarası ve ele 
gelen kitle yakınmasıyla başvurdu. Fizik muayenesinde sağ meme areola üzerinde, nipple komșuluğunda yüzeyi kurutlu, sert, kitlesel lezyon, cilt tutulumu göstermekteydi. Ultrasonografi ve mamografi ile kitlenin 28 × $25 \mathrm{~mm}$ çapında, düzensiz sınırlı olduğu, başka bir noktada mikrokalsifikasyonun bulunmadığ 1 gözlendi. Kalın iğne doku biyopsisi öncesinde manyetik rezonans görüntüleme yapıld1, tümörün çap1 doğruland1, cilt tutulumu gösterdiği anlaşıld1. Yapılan biyopside östrojen ve progesteron reseptörü pozitif, c-erb2 negatif, Ki-67 indeksi $\% 15$ olan invaziv karsinom belirlendi. Luminal a tümör sınıfında yer alan kitle için pozitron emisyon tomografi görüntülemesi yapıldı ve hastalığın sistemik yayılım yapmadığı anlaşıldı. Onkoloji konseyinde görüşülerek, cerrahi tedavi yapılmasına karar verildi. Nipple areola kompleksini tutan ve $3 \mathrm{~cm}$ 'den küçük tümörü bulunan hastaya Batwing Mastopeksi ile onkoloplastik meme cerrahisi yapılması kararlaştırıldı.

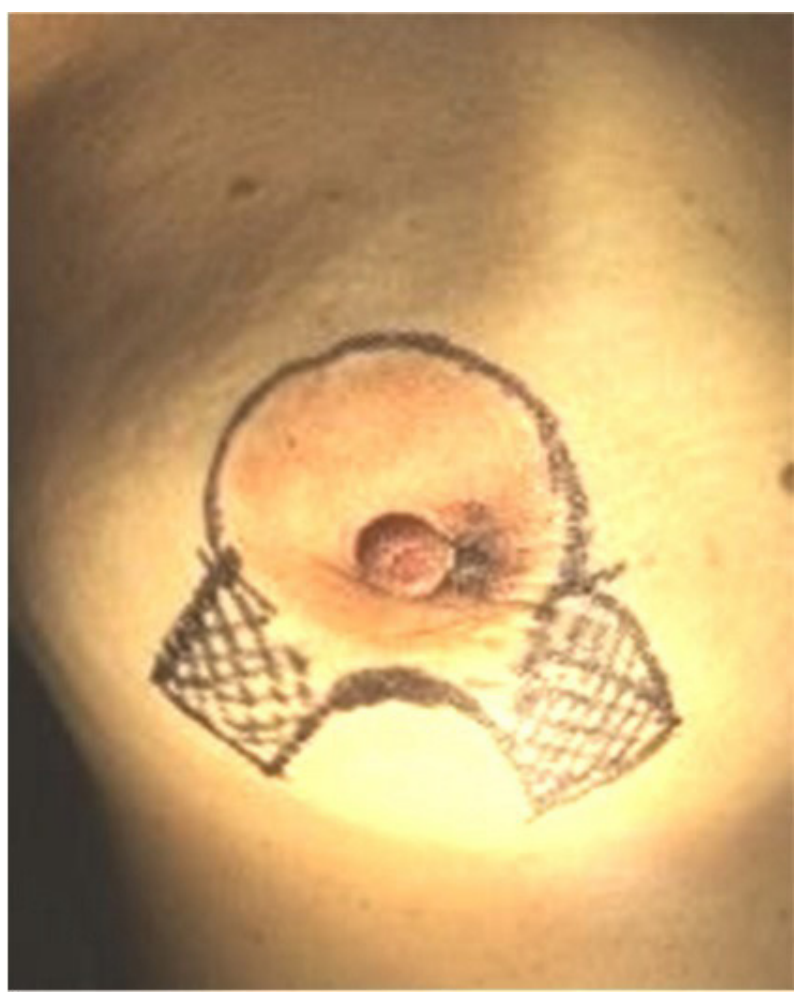

Resim 1: Meme başı tutulumu olan meme kanserinde Batwing Mastopeksi çizimi.

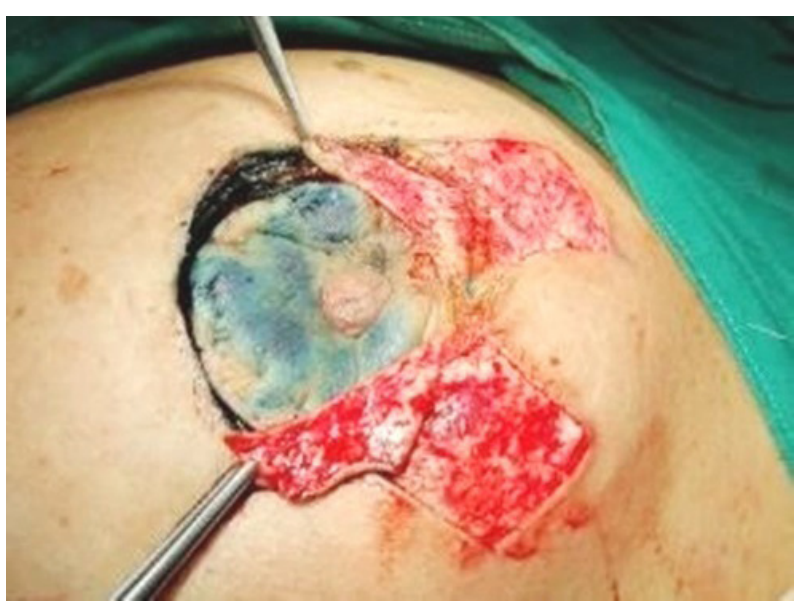

Resim 2: Deepitelizasyon alanı ve santral yerleşimli tümörün eksizyonu.
Uygun çizim sonrasında subareolar bölgeye $5 \mathrm{cc}$ isosulfan blue injeksiyonu yapıld 1 ve sağ aksilladan alınan sentinel lenf nodunda metastaz saptanmad1.Aksiller diseksiyon yapılmadı, onkoplastik cerrahi Batwing mastopeksi tekniğine uygun olarak yapıld1, dren kullanılmad1 (Resim 1-5).

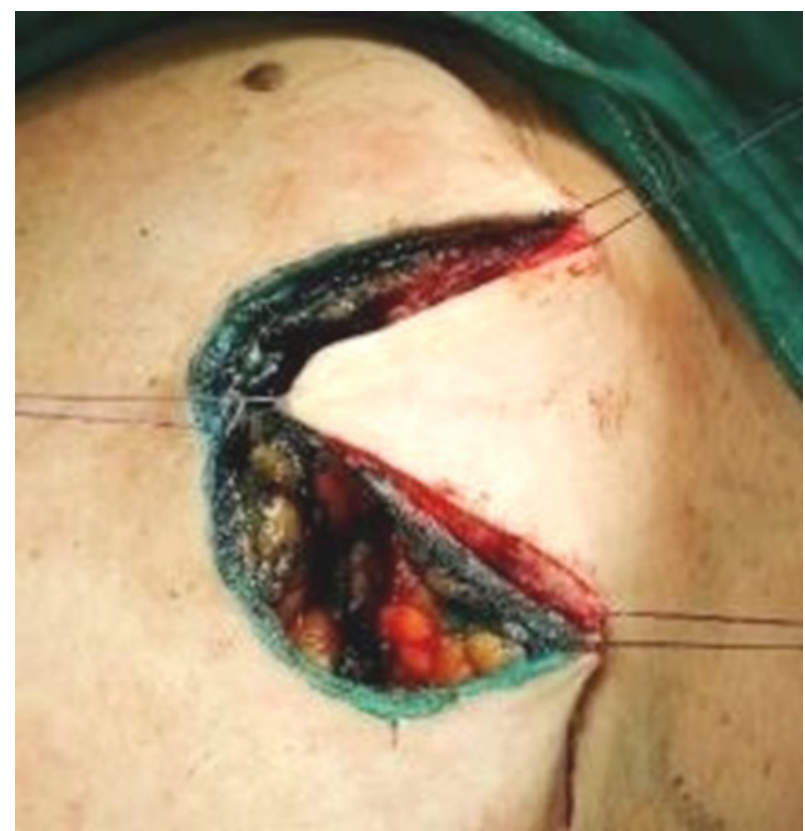

Resim 3: Eksizyon sonrası alt flebin, santral eksizyon alanına kaydırılması.

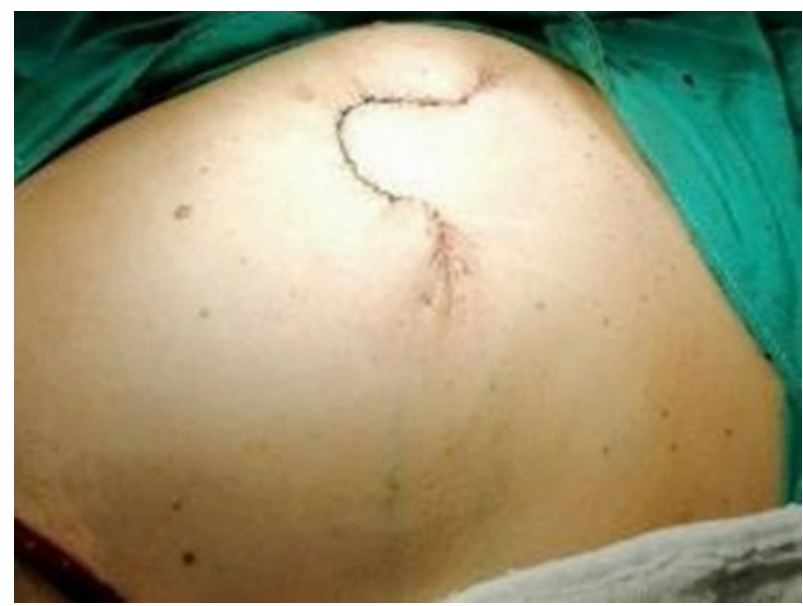

Resim 4: Yeniden șekillendirme sonrasında nipple areola alanınin flep ile kapatılması.

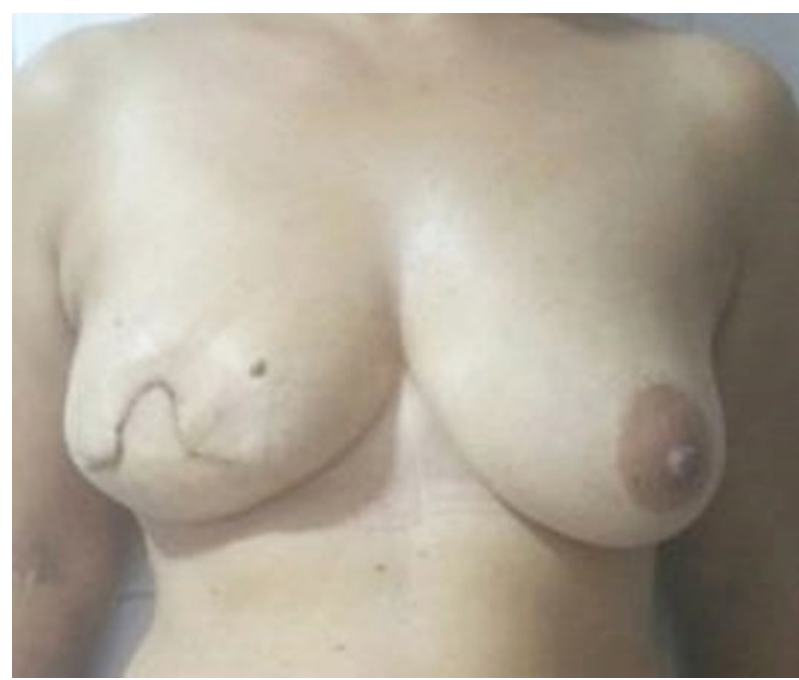

Resim 5: Hastanın ameliyat sonrası ikinci haftadaki görüntüsü. 
Alınan lumpektomi piyesinde cerrahi sınırların negatif olduğu belirtildiği için ameliyat sonlandırıld1. Patoloji sonucunda $30 \times 25 \mathrm{~mm}$ çapında, invaziv lobuler karsinomda, östrojen ve progesteron reseptörleri pozitif, c-erb2 negatif ve Ki67 indeksi $\% 40$ düzeyinde tespit edildi. Ki67 indeksi kalın iğne doku biyopsisi sonucundan farklı düzeyde saptand1. Adjuvan kemoterapi, radyoterapi ve hormonoterapi uygulanması ortak görüş olarak kararlaştırıldı. Hasta memenin görünümünden memnun olduğunu belirtti. Onkolojik tedavi tamamlandıktan sonra yeni bir nipple areola kompleksi yapılması planlandı.

\section{TARTIŞMA}

Onkoplastik meme cerrahisi teknikleri, tümör boyutu küçük olan ve yeterli hacme sahip memelerde uygulanmamaktadır. Oysa memenin hacmine göre çıkarılan kitlenin boyutu büyükse yapılması gerekmektedir. Lumpektomi piyeslerinde genellikle 20-40 g kadar meme dokusu ç1karılmaktadır. 80 g'dan fazla meme dokusu çıkarıldığında kozmetik açıdan olumsuz görünümle karşılaşılmaktadır. Meme hacminin \%20'sinden fazlasinin eksizyonu, böyle bir durumda oluşan doku kaybının kapatılması, memenin görünümünü bozmaktadır. Oluşan olumsuzluklar; cildin çukurlaşması, nipple areola kompleksinin yer değiştirmesi ve meme konturunun bozulmasıdır. Böylesi değişiklikler ameliyattan sonraki 3-6 ay içerisinde görülmeyebilir. Memenin görüntüsünün korunmasına yönelik uygulanan onkoplastik meme cerrahisi teknikleri ile eksizyon sonrası boşluk, etraf meme dokusunun hareketlendirilmesi ile kapatılabilmektedir. Bu sayede memenin toplam hacminin \%20-50'sinin ya da 200-1000 g kadar meme dokusunun çıkarılması mümkün olabilmektedir. Meme koruyucu cerrahi geçiren hastalarda oluşan olumsuz görünümün giderilmesinde de onkoplastik cerrahi oldukça faydalıdır [6-10].

Diğer önemli uygulama alanı, kanserli alanın yerleșiminden dolayı eksizyon sonrası nipple areola kompleksinin yeniden konumlandırmasinın gerekmesidir. Makromasti ya da meme pitozisi olan hastalarda oluşan estetik kaygıların giderilmesine iyi bir çözümdür. Bu sayede memenin doğal görünümü sağlanabilmekte ve pitozis düzeltilebilmektedir. Yine bu teknikler her türlü aksiller evrede uygulanabilmektedir. Özellikle aksillaya yakın, üst dış yerleşimli tümörlerde bu durum daha da önem kazanmaktadir.

Batwing mastopeksi onkoplastik tekniklerden biridir ve her büyüklükteki memede yapılabilmektedir. $3 \mathrm{~cm}$ 'den küçük, santral yerleşimli veya memenin üst yarısında cildi tutan meme tümörlerinde ve Paget's hastalığında tercih edilmektedir. Ciltte $3 \mathrm{~cm}$ 'yi aşan tümör varlığında, inflamatuar meme kanserinde, T3 evreli tümörlerde ve multisentrik hastalıkta yapılması kontrendikedir.

Tümör boyutunun onkoplastik cerrahi için uygun olmadığ 1 durumlarda neoadjuvan kemoterapi uygulanması iyi bir seçenek olabilmektedir. Daha önce radyasyon tedavisi almış, steroid tedavisi altında olan, morbid obez ve zayıf cilt yapısına sahip kişilerde cerrahi açıdan dikkatli olunmalıdır.

\section{SONUÇ}

Başarılı bir onkoplastik cerrahi tedavi için doğru hesaplama, uygun çizim, iyi yara bakımı, ameliyat esnasinda doğru pozisyonlama ve gerektiğinde dren kullanılması önemlidir. Elde edilen güvenli cerrahi sınırlar ve düzgün estetik görünüm, hasta memnuniyetini ve hayat kalitesini arttırmaktadır. Her cerrahın hasta ile bu konuları doğru şekilde konuşması ve konu hakkında bilinçlendirmesi mesleki gerekliliktir. Tekniklerin olumlu sonuçlarının görülmesi, hastayı ve ameliyatı yapan cerrahı memnun edecektir.

\section{KAYNAKLAR}

1- $\quad$ Pesce CE, Liederbach E, Czechura T, et al. Changing surgical trends in young patients with early stage breast cancer, 2003 to 2010: a report from the National Cancer Data Base. J Am Coll Surg 2014; 219: 19.

2- $\quad$ Clough KB, Kaufman GJ, Nos C, et al. Improving breast cancer surgery: a classification and quadrant per quadrant atlas for oncoplastic surgery. Ann Surg Oncol 2010; 17: 1375.

3- Urban C, Anselmi KF, Kroda F, et al. Oncoplasty as the standard of care in breast cancer surgery. Eur Oncol Haematol 2014; 10: 43.

4- Weber WP, Soysal SD, El-Tamer M, et al. First international consensus conference on standardization of oncoplastic breast conserving surgery. Breast Cancer Res Treat 2017; 165:139.

5- $\quad$ Noguchi M, Yokoi-Noguchi M, Ohno Y, et al. Oncoplastic breast conserving surgery: Volume replacement vs. volume displacement. Eur J Surg Oncol 2016; 42:926.

6- $\quad$ Silverstein MJ. An argument against routine use of radiotherapy for ductal carcinoma in situ. Oncology (Williston Park) 2003; 17: 1511.

7- $\quad$ Carter SA, Lyons GR, Kuerer HM, et al. Operative and Oncologic Outcomes in 9861 Patients with Operable Breast Cancer: Single-Institution Analysis of Breast Conservation with Oncoplastic Reconstruction. Ann Surg Oncol 2016; 23: 3190.

8- Clough KB, Lewis JS, Couturaud B, et al. Oncoplastic techniques allow extensive resections for breast-conserving therapy of breast carcinomas. Ann Surg 2003; 237: 26.

9- De La Cruz L, Blankenship SA, Chatterjee A, et al. Outcomes After Oncoplastic Breast-Conserving Surgery in Breast Cancer Patients: A Systematic Literature Review. Ann Surg Oncol 2016; 23: 3247.

10- Down SK, Jha PK, Burger A, Hussien MI. Oncological advantages of oncoplastic breast-conserving surgery in treatment of early breast cancer. Breast J 2013; 19: 56. 